\title{
HLA Class II Defects in Burkitt Lymphoma: Bryostatin-1-Induced 17 kDa Protein Restores CD4+ T-Cell Recognition
}

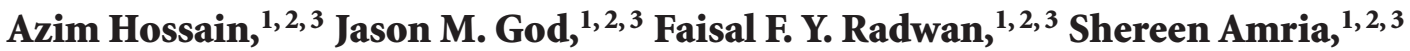 \\ Dan Zhao, ${ }^{1,2,3}$ Jennifer R. Bethard, ${ }^{2,3,4}$ and Azizul Haque ${ }^{1,2,3}$ \\ ${ }^{1}$ Department of Microbiology and Immunology, Medical University of South Carolina, 173 Ashley Avenue, \\ Charleston, SC 29425, USA \\ ${ }^{2}$ Hollings Cancer Center, Medical University of South Carolina, 173 Ashley Avenue, Charleston, SC 29425, USA \\ ${ }^{3}$ Charles P. Darby Children's Research Institute, Medical University of South Carolina, 173 Ashley Avenue, \\ Charleston, SC 29425, USA \\ ${ }^{4}$ Department of Cell and Molecular Pharmacology and Experimental Therapeutics, Medical University of South Carolina, \\ 173 Ashley Avenue, Charleston, SC 29425, USA
}

Correspondence should be addressed to Azizul Haque, haque@musc.edu

Received 9 August 2011; Accepted 5 September 2011

Academic Editor: W. Kast

Copyright ( $) 2011$ Azim Hossain et al. This is an open access article distributed under the Creative Commons Attribution License, which permits unrestricted use, distribution, and reproduction in any medium, provided the original work is properly cited.

\begin{abstract}
While the defects in HLA class I-mediated Ag presentation by Burkitt lymphoma (BL) have been well documented, CD4+ Tcells are also poorly stimulated by HLA class II Ag presentation, and the reasons underlying this defect(s) have not yet been fully resolved. Here, we show that BL cells are deficient in their ability to optimally stimulate CD4+ T cells via the HLA class II pathway. The observed defect was not associated with low levels of BL-expressed costimulatory molecules, as addition of external costimulation failed to result in BL-mediated CD4+ T-cell activation. We further demonstrate that BL cells express the components of the class II pathway, and the defect was not caused by faulty Ag/class II interaction, because antigenic peptides bound with measurable affinity to BL-associated class II molecules. Treatment of BL with broystatin-1, a potent modulator of protein kinase $\mathrm{C}$, led to significant improvement of functional class II Ag presentation in BL. The restoration of immune recognition appeared to be linked with an increased expression of a $17 \mathrm{kDa}$ peptidylprolyl-like protein. These results demonstrate the presence of a specific defect in HLA class II-mediated Ag presentation in BL and reveal that treatment with bryostatin-1 could lead to enhanced immunogenicity.
\end{abstract}

\section{Introduction}

Burkitt lymphoma (BL) is an aggressive non-Hodgkin's Bcell malignancy, occurring most frequently as endemic BL in children living in areas of high malarial prevalence [1]. This malignancy may also be found in other parts of the world as sporadic BL and accounts for $1-2 \%$ of all lymphomas in Western countries [1]. The clinical manifestations of $\mathrm{BL}$ are variable, with tumors of the jaw characteristically seen in endemic $\mathrm{BL}$ and tumors in the gut associated with sporadic BL [2-4]. BL has one of the fastest doubling times among human malignancies and is frequently associated with immune deficiency [3].
In addition to its strong association with malaria, BL has a high correlation with Epstein-Barr Virus (EBV). EBV infection, however, is not requisite for the development of $\mathrm{BL}$, and the degree of association with EBV varies based on the type of BL. EBV infection occurs in $>90 \%$ of endemic BL cases, $10-15 \%$ of sporadic BL, and $40 \%$ of human immunodeficiency virus (HIV) associated BL [1]. While the exact role that EBV plays in the development of $\mathrm{BL}$ remains largely unknown, it is understood that EBV gene products may be involved in the transformation of BL cells and their decreased immunogenicity. Additional evidence for EBV having a role in development of BL stems from EBV's link to various other lymphoid malignancies including 
Hodgkin's lymphoma, transplant-related B-cell lymphomas, T-cell lymphomas, adult T-cell leukemia, and natural killer cell leukemia [5-8]. While BL has varying associations with malaria and EBV and in some cases is not associated with either, the one feature shared by all BLs is overexpression of the oncogenic transcription factor $c$-myc, which has a gene network comprising up to $15 \%$ of all known genes [9]. This abnormality results from the translocation of the MYC gene to an immunoglobulin locus leading to its constitutive activation [10-12].

$\mathrm{BL}$ is known to be deficient in HLA class I-mediated antigen (Ag) presentation to CD8+ T lymphocytes [13-15]. However, the role of HLA class II-mediated Ag presentation in generating an immune response to $\mathrm{BL}$ has not been fully elucidated. The class I defect has been well studied and is understood to result from the weak immunogenicity of EBV nuclear Ag 1 (EBNA1), which is poorly processed and presented through the class I pathway [16-18]. Another EBV gene product, gp42, has a role in mediating virus binding through interaction with HLA class II and it has been speculated to block the interaction between class II and the T-cell receptor $[19,20]$. Although HLA class I-mediated activation of CD8+ T cells leads to Ag-specific lysis of tumor cells, an HLA class II response is vital for the generation of sustained immune responses [21]. Our laboratory has previously shown that B-cell lymphomas are deficient in HLA class II-mediated Ag presentation [22], and in this study we explore the role of B-cell-associated molecules in restoration of CD4+ T-cell recognition of BL cells.

The study presented here suggests that multiple defects may contribute to BL's inability to efficiently present $\mathrm{Ag}$ via HLA class II molecules. We confirm expression of a transfected HLA class II allele in both BL cells and EBV-immortalized B-lymphoblastoid cells (B-LCL), and demonstrate that the transfected HLA class II efficiently binds exogenously delivered $\mathrm{Ag}$ to form class II peptide complexes. However, while B-LCL were capable of CD4+ Tcell stimulation, BL cells were deficient in their ability to do so, and addition of external co-stimulation was insufficient to overcome this defect. In addition, treatment of BL cells with bryostatin-1 partially restored class II-mediated Ag presentation. This restoration was linked to the upregulation of a $17 \mathrm{kDa}$ protein in bryostatin-treated $\mathrm{BL}$ which was expressed at low levels in untreated BL but highly expressed in B-LCL, suggesting that this protein may play a role in enhancing class II-mediated $\mathrm{Ag}$ presentation. In other studies, bryostatin-1 has been shown to increase HLA class II expression in dendritic cells and in a colorectal carcinoma cell line, but its effect on HLA class II expression and Ag presentation in lymphoid malignancies has not previously been evaluated $[23,24]$. On the whole, these results suggest that BL possesses multiple defects which lead to an impaired ability to stimulate CD4+ T cells through HLA class II Ag presentation. These defects may provide the opportunity to develop novel immunotherapies leading to more targeted treatment of $\mathrm{BL}$ and other lymphoid malignancies. This study also provides a rationale for the further evaluation of bryostatin-1 as a therapeutic treatment of lymphoid malignancies.

\section{Materials and Methods}

2.1. Cell Lines. Human BL cell lines, Nalm-6, Ramos, and Ous, were maintained in complete RPMI-1640 supplemented with 10\% fetal bovine serum (Invitrogen, Carlsbad, CA), $50 \mathrm{U} / \mathrm{mL}$ penicillin $50 \mu \mathrm{g} / \mathrm{mL}$ streptomycin, and $1 \% \mathrm{~L}-$ glutamine (Mediatech, Manassas, VA). The Ous cell line was a gift from Dr. Christian Munz (Rockefeller University). The human B-lymphoblastoid cell lines (B-LCL) 6.16 and Frev were maintained in IMDM supplemented with $10 \%$ bovine growth serum (Hyclone, Logan, UT), $50 \mathrm{U} / \mathrm{mL}$ penicillin $50 \mu \mathrm{g} / \mathrm{mL}$ streptomycin, and $1 \%$ L-glutamine (Mediatech). Nalm-6, Ramos, and 6.16 cells were retrovirally transfected for constitutive expression of HLA-DR4 (DRB1*0401) with linked drug selection markers for hygromycin and histidinol resistance to generate Nalm-6.DR4, Ramos.DR4, and 6.16.DR4 $[22,25]$. Frev did not require transfection of the class II allele as it constitutively expresses HLA-DR4. Surface HLA-DR4 expression in the transfectants was confirmed by flow cytometric analysis using the DR4-specific mAb, 359F10 [22, 26, 27]. 6.16.DR4 cells were further transfected with $\mathrm{DM} \alpha$ and $\mathrm{DM} \beta$ for constitutive expression of HLA-DM molecules to generate 6.16.DR4.DM [22]. The expression of HLA-DM on 6.16.DR4.DM cells was confirmed by western blotting. T-cell hybridomas $2.18 \mathrm{a}$ and 1.21 recognize Ig $\kappa$ residues $188-203$ and $145-159$, respectively, and were generated by immunization of DR4-transgenic mice as described $[25,28]$. The T-cell hybridoma 17.9 (generously provided by D. Zaller, Merck Research Laboratories, Rahway, $\mathrm{NJ}$ ) responds to human serum albumin (HSA) residue 64$76 \mathrm{~K}$ [29]. These T cell hybridomas are less dependent on costimulatory signals for their stimulation. Cells were cultured in RPMI 1640 with $10 \%$ FBS, $50 \mathrm{U} / \mathrm{mL}$ penicillin, $50 \mu \mathrm{g} / \mathrm{mL}$ streptomycin, and $50 \mu \mathrm{M} \beta$-mercaptoethanol (Invitrogen).

2.2. Antigens, Peptides, and Other Reagents. Human serum albumin (HSA) and human IgG kappa (IgG $\kappa$ ) were purchased from Sigma (St. Louis, MO). HSA $_{64-76 \mathrm{~K}}$ peptide (sequence: VKLVNEVTEFAKTK) human IgG immunodominant peptide $\kappa_{188-203} \quad(\kappa \mathrm{I}$; sequence: KHKVYACEVTHQGLSS), and subdominant peptide $\kappa_{145-159}$ ( $\kappa \mathrm{II} ;$ sequence: KVQWKVDNALQSGNS) were produced using Fmoc technology and an Applied Biosystems Synthesizer as described, dissolved in PBS, and stored at $-20^{\circ} \mathrm{C}$ until used $[25,29,30]$. Reverse phase HPLC purification and mass spectrometry were used to analyze the peptide and showed a peptide purity $>99 \%$. Bryostatin-1 was purchased from Sigma.

2.3. Antigen Presentation Assays. B-LCL and BL were incubated with $0 \mu \mathrm{M}, 5 \mu \mathrm{M}, 10 \mu \mathrm{M}$, or $20 \mu \mathrm{M}$ HSA Ag or HSA synthetic peptide for $3-24 \mathrm{~h}$ at $37^{\circ} \mathrm{C}$ in the appropriate cell culture media to determine optimal antigen concentrations to use in antigen presentation assays [22, 25]. Following titration, the same assays were carried out using only the optimal concentration of each antigen. Cells were then washed and co-cultured with the T-cell hybridoma 17.9 for $24 \mathrm{~h}$ at $37^{\circ} \mathrm{C}$. In parallel assays, $2.18 \mathrm{a}$ and 1.21 were 
stimulated with anti-CD3/CD28 prior to co-culture with Nalm-6.DR4, Ramos.DR4, or 6.16.DR4.DM which had been incubated with $\kappa$ I or $\kappa$ II [29]. Following co-culture, T cell production of IL-2 was quantitated by ELISA [31]. Assays were repeated in triplicate with standard error for triplicate samples within a single experiment being reported.

2.4. Western Blotting. Western blot analysis was performed on whole cell lysates of Frev, Nalm-6.DR4, 6.16.DR4.DM, and Ramos.DR4. Expression of HLA class II, Ii, and HLADM was analyzed as described previously $[32,33]$. Densitometry was performed using a ChemiDoc XRS station (Bio-Rad) where the protein bands were analyzed using the Quantity One 4.6.3 software (Bio-Rad). Relative protein expression levels were stated as a ratio of specific proteins expressed $/ \beta$-actin for each sample. Data are representative of at least three separate experiments.

2.5. IL-2 ELISA. IL-2 levels in Ag presentation assay supernatant were quantitated by ELISA. A 96-well ELISA plate was coated overnight at $4^{\circ} \mathrm{C}$ with purified rat anti-mouse IL-2 (Sigma). The plate was then washed and blocked with $2 \%$ BSA at RT for $30 \mathrm{~m}$. After washing, standards and samples were plated in appropriate wells and incubated at RT for $2 \mathrm{~h}$. A standard curve was generated using recombinant IL2 purchased from R\&D (Minneapolis, MN). The plate was washed, and biotinylated rat anti-mouse IL-2 (Sigma) was added and incubated at RT for $1 \mathrm{~h}$. Following washing, avidin peroxidase (Pierce, Rockford, IL) was added to each well and incubated at RT for $30 \mathrm{~m}$. The plate was washed, and PNPP substrate (Thermo Scientific, Rockford, IL) was added to each well and incubated at RT. Readings were taken every $30 \mathrm{~m}$ at $405 \mathrm{~nm}$. IL-2 levels in sample wells are expressed in $\mathrm{pg} / \mathrm{mL}$, calculated from the standard curve. Assays were repeated in triplicate and expressed as mean IL- \pm SEM.

2.6. Peptide Binding Assays. Nalm-6.DR4, Ramos.DR4, 6.16.DR4.DM, and Frev cells were fixed in 1\% paraformaldehyde and then incubated overnight with $0 \mu \mathrm{M}, 10 \mu \mathrm{M}$, or $20 \mu \mathrm{M}$ biotinylated HSA peptide (b-HSA) in $150 \mathrm{mM} \mathrm{CPB}$ (pH 7.4), washed with PBS, and lysed on ice for $20 \mathrm{~min}$ with $50 \mathrm{mM}$ Tris buffer ( $\mathrm{pH} 8)$ containing $0.15 \mathrm{M} \mathrm{NaCl}$ and $0.5 \%$ IGEPAL CA 630 (Sigma) as described [30, 34]. Cell supernatants were added to plates (Costar, Cambridge, MA) previously coated overnight with the anti-human class II antibody 37.1 (kindly provided by L. Wicker, Merck Research Lab, Rahway, NJ). The captured class II-peptide complexes were detected with europium-labeled streptavidin (Pharmacia Fine Chemicals, Piscataway, NJ) using a fluorescence plate reader (Delfia, Wallac, Turku, Finland). The number of total DR molecules within B-LCL/BL cells was quantitated as described [28].

2.7. Bryostatin-1 Treatment of BL Cells. Nalm-6.DR4 and Ramos.DR4 were treated with 0,20 , or $40 \mathrm{nM}$ of bryostatin1 for overnight. Following incubation, untreated and bryostatin-treated cells were used in Ag presentation assays with HSA peptide followed by ELISA IL-2 quantitation as already described. In separate assays, Ramos.DR4 were treated with $40 \mathrm{nM}$ bryostatin overnight and then fixed in $1 \%$ paraformaldehyde for $5 \mathrm{~min}$. Following fixation, the cells were washed and incubated with $0 \mu \mathrm{M}, 10 \mu \mathrm{M}$, or $40 \mu \mathrm{M}$ of b$\mathrm{HSA}$ for $3 \mathrm{~h}$ at $37^{\circ} \mathrm{C}$ with shaking. The cells were then washed and lysed in Hanks Balanced Salt Solution with 1\% Triton-X100 and protease inhibitors (PMSF and TLCK). The lysate was added to wells of a 96-well plate precoated with the anti-HLA class II antibody, 37.1. Captured class II peptide complexes were detected using streptavidin peroxidase and BD OptEIA TMB substrate reagents (BD, San Diego, CA). The reaction was stopped using $1 \mathrm{M}$ phosphoric acid and the resulting absorbance was read at $450 \mathrm{nM}$.

Additionally, surface protein expression in 6.16.DR4. DM, untreated Nalm-6.DR4, and bryostatin-treated Nalm6.DR4 was evaluated by SDS-PAGE protein separation. Nalm-6.DR4 cells were treated overnight with $40 \mathrm{nM}$ of bryostatin-1. Following incubation, 6.16.DR4.DM, untreated Nalm-6.DR4, and bryostatin-treated Nalm-6.DR4 were washed in citrate phosphate buffer $(\mathrm{CPB})$ to elute cell surface proteins. The resulting eluate was then subjected to SDS-PAGE. A $17 \mathrm{kDa}$ band was excised from these gels and analyzed by MALDI TOF-TOF mass spectrometry. Proteins in CPB eluate from 6.16.DR4.DM were separated by electrophoresis on large, nonreducing gels. The $17 \mathrm{kDa}$ band was excised and the protein was extracted by sonication in PBS on ice. Ramos.DR4 cells were incubated with the HSA peptide in the $17 \mathrm{kDa}$ extract for use in $\mathrm{Ag}$ presentation assays as described. T cell production of IL- 2 was quantitated [31].

2.8. Protein Extraction and Digestion. $\mathrm{CPB}$ eluate was obtained from 6.16.DR4.DM, untreated Nalm-6.DR4, and bryostatin-treated Nalm-6.DR4 as described previously [22]. Extracts were concentrated, and protein concentrations were measured, then run on a non-reducing gel, and stained with Coomassie blue. Gel plugs were excised and placed in an eppendorf tube. Each plug was washed with $50 \mathrm{mM}$ ammonium bicarbonate for 10 minutes. Next, the plugs were destained using $25 \mathrm{mM}$ ammonium bicarbonate in $50 \%$ acetonitrile for 15 minutes. The plugs were dehydrated with 100\% acetonitrile for 15 minutes and dried in a speedvac. Each gel plug was covered with Proteomics Grade Trypsin (Sigma) and incubated at $37^{\circ} \mathrm{C}$ overnight. The supernatant was collected in a clean dry eppendorf tube. Peptides were further extracted with 1 wash of $25 \mathrm{mM}$ ammonium bicarbonate for 20 minutes and three washes of $5 \%$ formic acid, 50\% acetonitrile for 20 minutes each. The supernatent was collected and pooled after each wash then dried down in a speedvac to $\sim 1 \mathrm{uL}$. Prior to analysis, the samples were reconstituted with $10 \mathrm{uL}$ of $0.1 \%$ trifluoroacetic acid. Samples were then concentrated with a C18 Ziptip (Millipore) and eluted with $0.1 \%$ TFA, 50\% acetonitrile, and $7.0 \mathrm{mg} / \mathrm{mL} \alpha$-cyano-4-hydroxycinnamic acid directly onto the MALDI target.

2.9. Mass Spectrometric Analysis (MALDI TOF/TOF). After the spots were dried completely, the plate was loaded into the 


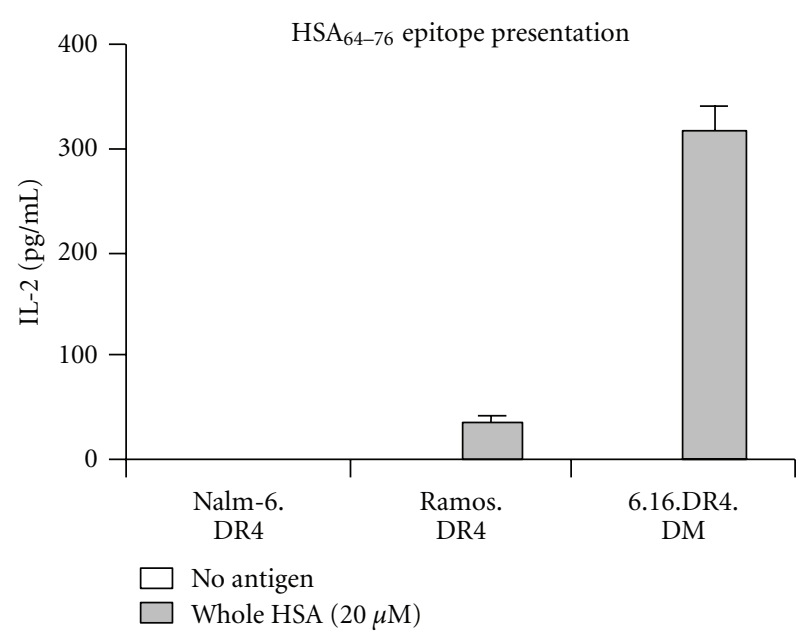

(a)

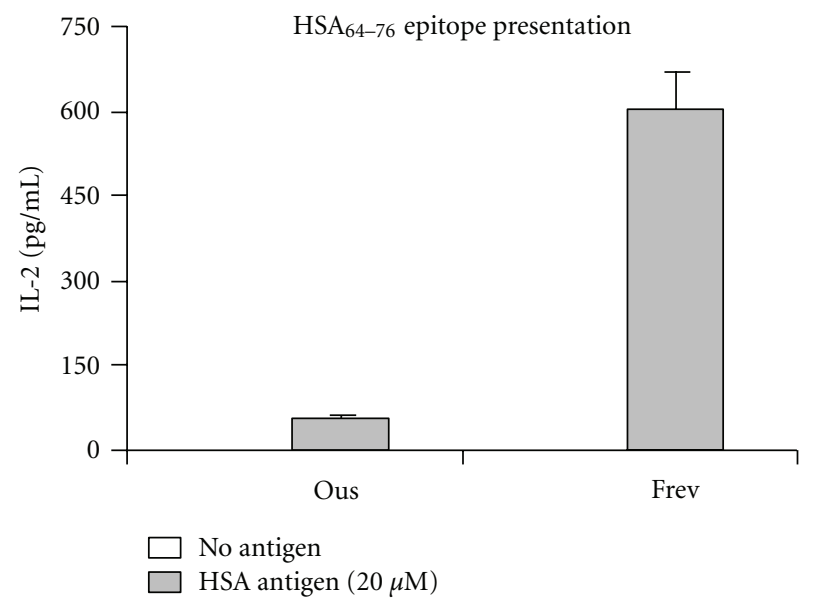

(c)

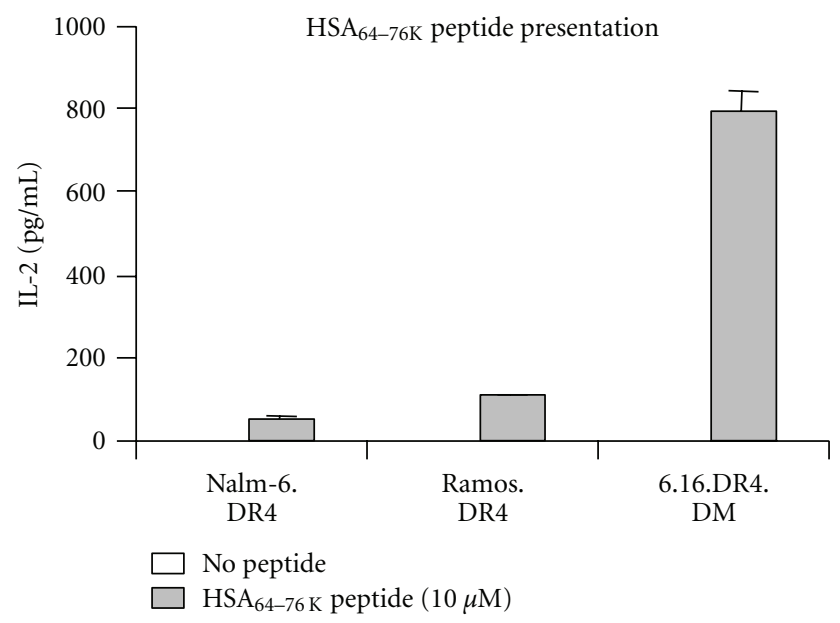

(b)

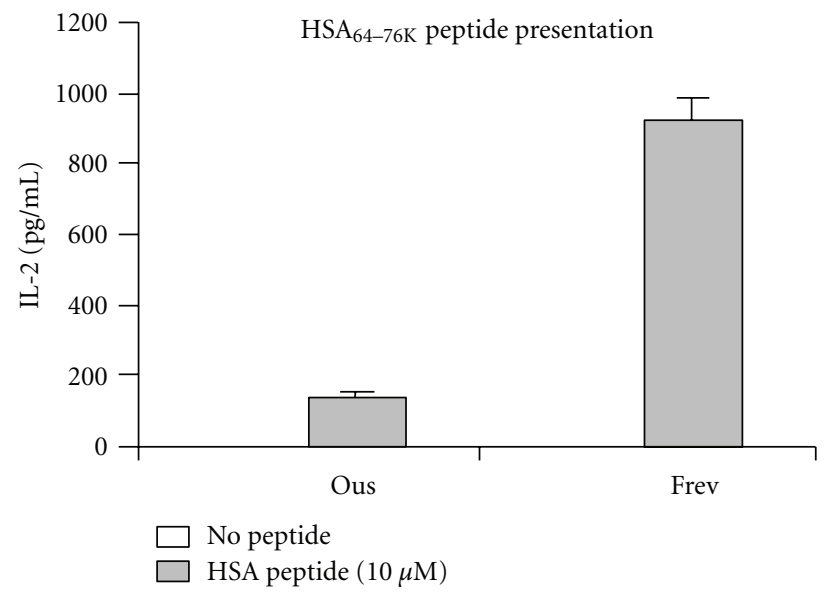

(d)

FIGURE 1: BLs are deficient in their ability to present Ag in the context of HLA class II. BL (Nalm-6.DR4, Ramos.DR4, and OUS) and B-LCL (6.16.DR4.DM and Frev) were incubated with whole HSA (a and c) or HSA synthetic peptide (b and d). Following incubation, cells were washed and co-cultured with the HSA $_{64-76 \mathrm{k}}$ epitope-specific T-cell hybridoma 17.9. Supernatant from the co-culture was assayed by ELISA to determine IL-2 levels as a measure of T-cell stimulation. All three BL cell lines were deficient in stimulation of IL-2 production for both whole HSA and HSA synthetic peptide, while both B-LCL efficiently presented each Ag to stimulate high levels of IL-2 production.

Applied Biosystems 4800 Proteomics Analyzer. An external calibration was performed prior to analyzing samples utilizing the manufacturer's standards and protocols. Samples were analyzed in batch mode using 2000 laser shots per spectrum. First, peptide mass maps were acquired over the $\mathrm{m} / \mathrm{z}$ range of $800-3500$ in reflectron mode with a delayed extraction time optimized for $\mathrm{m} / \mathrm{z} 2000$ by averaging 2000 scans to locate peaks of peptide origin. The next batch run performed MS-MS analyses to obtain sequence data on the 20 most abundant peaks from the MS analysis. Upon completion of the batch processing, the data was exported into the GPS Explorer data processing system for interpretation and identification. The MASCOT databasesearching algorithm analyzed the data and summarized the results in report format. Database searches were performed using 2 missed cleavages and one differential modification of methionine oxidation. The top 20 matches were reviewed prior to assigning confident protein identifications.

\section{Results}

3.1. BL Cells Display Decreased HLA Class II-Mediated CD4+ T-Cell Stimulation. Although BL and B-LCL both express surface HLA class II, we transfected these cell lines to express a common class II allele so that we might obtain a more direct comparison of class II-mediated Ag presentation between the two cell types. Retroviral gene transfections of a DR4 allele, HLA DRB ${ }^{*} 0401$, were carried out on our BL (Nalm- 6 and Ramos) and B-LCL (6.16) cell lines. Flow cytometric analysis confirmed transfection and expression of this allele in all three cell lines (data not shown). 6.16.DR4 cells were additionally transfected with HLA-DM to generate 6.16.DR4.DM cells expressing similar levels of HLA-DM when compared to Nalm-6.DR4 and Ramos.DR4 [33]. Transfectants were then sorted, matched for surface DR4 expression, and incubated, along with Ous and Frev, in culture media with either HSA antigen or HSA peptide. Following incubation, cells were 


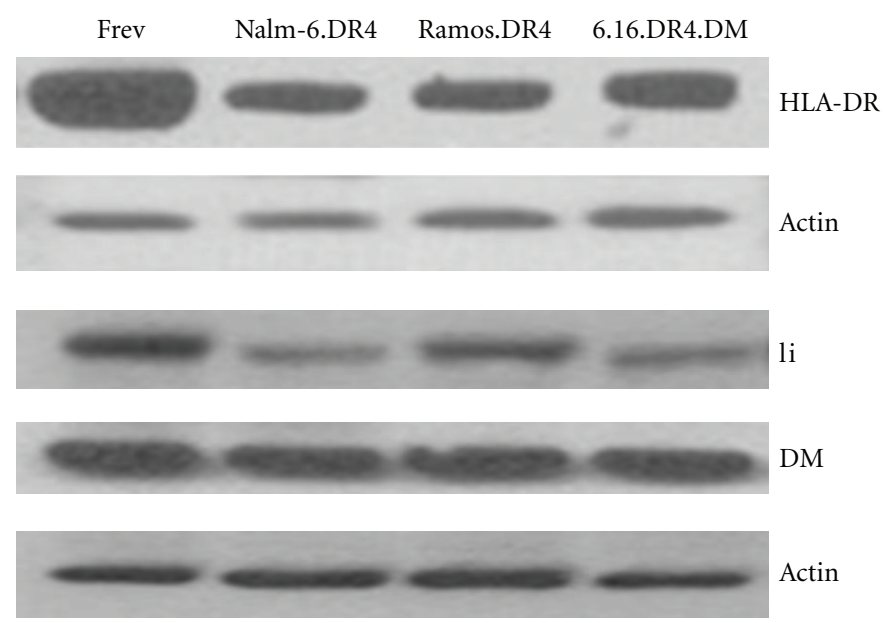

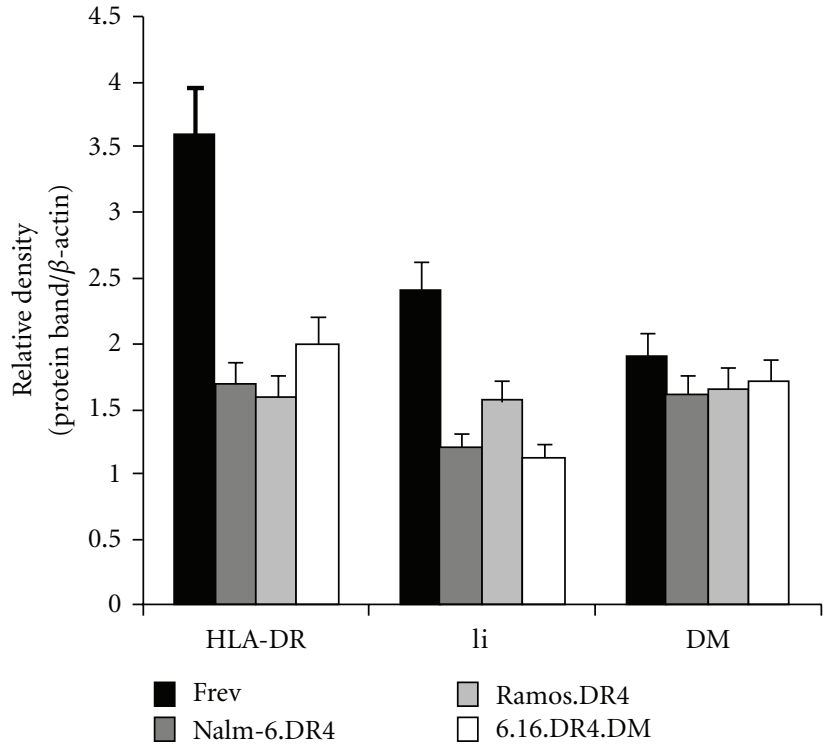

(b)

Figure 2: BL and B-LCL express similar levels of HLA class II pathway components. Variations in efficiency of Ag presentation between BL and B-LCL may be attributable to differences in expression levels of components in the class II pathway. To evaluate this possibility, the BL cell lines Nalm-6.DR4 and Ramos.DR4, the B-LCL cell lines 6.16.DR4.DM and Frev were analyzed by western blotting for expression of HLA class II, invariant chain (Ii), and HLA-DM (a). Densitometric analysis confirmed the expression of comparable levels of each of these class II pathway components (b).

washed and co-cultured with the T-cell hybridoma, 17.9, for $24 \mathrm{~h}$ at $37^{\circ} \mathrm{C}$. Culture supernatant was collected and assayed by ELISA for IL-2 levels. The results of these assays demonstrate that Nalm-6.DR4, Ramos.DR4, and Ous were deficient in their ability to stimulate IL-2 production in 17.9 by class II-mediated presentation of HSA epitope or HSA synthetic peptide (Figures 1(a)-1(d)). The B-LCL lines 6.16.DR4.DM and Frev, however, stimulated production of high levels of IL-2 (Figures 1(a)-1(d)). Supplemental Figure 1 (see Supplemental material available online at doi:10.1155/2011/585893) shows the results of whole HSA and HSA peptide titration with Nalm-6.DR4, Ramos.DR4 and 6.16.DR4.DM. Nalm-6.DR4 and Ramos.DR4 fail to stimulate IL-2 production at all concentrations of whole HSA or HSA peptide, while 6.16.DR4.DM shows a dosedependent increase in levels of IL-2 production. These results suggest that BL cells possess a defect(s) in the presentation of $\mathrm{Ag}$ to CD4+ T cells in the context of HLA class II.

3.2. BL and B-LCL Express Similar Levels of HLA Class II Pathway Components. Western blot analysis was performed on Nalm-6.DR4, Ramos.DR4, 6.16.DR4.DM, and Frev for expression of HLA class II, Ii, and HLA-DM. Data from these analyses revealed that both $\mathrm{BL}$ and B-LCL expressed detectable levels of these immune components (Figure 2(a)). As a wild type B-LCL, Frev expresses higher levels of class II pathway components than Nalm-6.DR4, Ramos.DR4, and 6.16.DR4.DM, as analyzed by densitometry and corrected for actin loading controls (Figure 2(b)). These data suggest that the observed defect in class II-mediated Ag presentation by $\mathrm{BL}$ is not the result of a defect in the HLA class II processing and presentation pathway.
3.3. Addition of External Co-Stimulation Is Insufficient to Overcome the BL-Associated Defect in Class II-Mediated Ag Presentation. It has previously been reported that BL cells are deficient in expression of co-stimulatory molecules (CD80/86). In order to determine if this was the cause of the defect in class II-mediated $\mathrm{Ag}$ presentation by BL, $\mathrm{Ag}$ presentation assays were performed in the presence of external co-stimulatory signals as described. In this assay, T-cell hybridomas were treated with anti-CD3/CD28 plus cross-linked IgG and co-cultured with the BL cells that were preincubated with HSA peptide. The addition of external co-stimulation had little to no effect on class II Ag presentation by BL (Figure 3). While 6.16.DR4.DM stimulated high levels of IL-2 production in $\mathrm{T}$ cells with or without external co-stimulation, Nalm-6.DR4 and Ramos.DR4 showed no significant increase in stimulation of IL-2 production in T cells with external co-stimulation.

3.4. HSA Peptide Binds with Similar Affinity to HLA Class II on $B L$ and $B-L C L$. The next step in evaluating the BL-related defect in HLA class II Ag presentation was to assess the binding efficiency of HSA peptide to BL-expressed surface DR4. Nalm-6.DR4, Ramos.DR4, 6.16.DR4.DM, and Frev were incubated with various concentrations of b-HSA at $\mathrm{pH}$ 7.4. Class II peptide complexes were then detected in an ELISA format using europium-labeled streptavidin. Data showed a dose-dependent response with each cell line binding b-HSA peptide with a similar, measurable affinity (Figure 4). These results suggest that BL's reduced capacity to present Ag via HLA class II is not a result of impaired peptide binding to HLA class II molecules. 


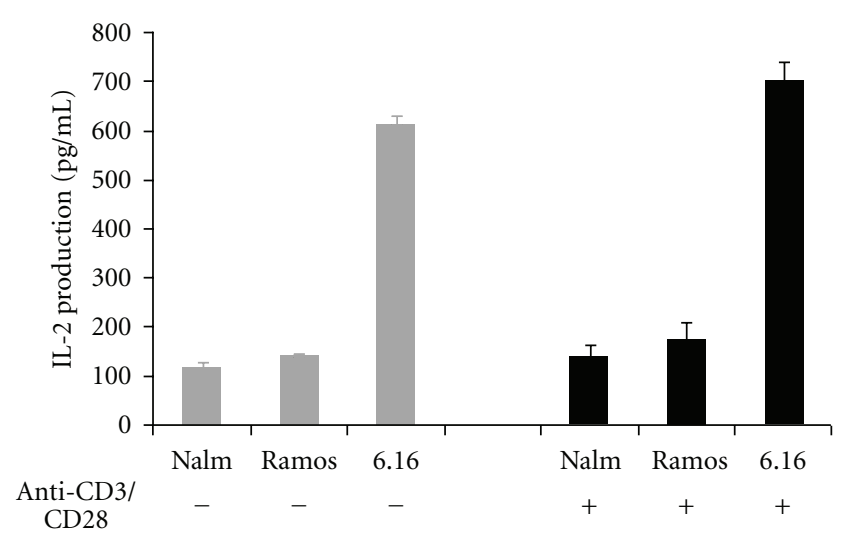

Figure 3: Addition of external co-stimulation is not sufficient to overcome class II-associated defects in BL. BLs are known to express lower levels of costimulatory molecules, raising the possibility that this was the cause of the observed defect in their ability to present Ag via class II. BL cell lines Nalm-6.DR4 and Ramos.DR4, and the BLCL cell line 6.16.DR4.DM were incubated with $\kappa$ I and $\kappa$ II peptides prior to co-culture with the T-cell hybridomas 2.18 a or 1.21 which had been stimulated with anti-CD3/CD28. Culture supernatant was assayed by ELISA for IL-2 levels as a measure of T-cell stimulation. These results demonstrate that Nalm-6.DR4 and Ramos.DR4 Ag presentation is unaffected by the addition of external co-stimulation and remains deficient in class II-mediated presentation.

\subsection{Bryostatin Treatment of BL Increases Peptide Binding} to HLA Class II and Restores Class II Ag Presentation and CD4+ T-Cell Recognition. Previous studies on bryostatin1 have shown that it causes upregulation of HLA class II molecules in the professional Ag presenting dendritic cells and leads to increased T-cell stimulation by these cells [23]. Based on this finding, we sought to determine if bryostatin1 treatment would impact Ag presentation by BL. Nalm6.DR4 and Ramos.DR4 cells were treated with bryostatin-1 overnight and then used in Ag presentation assays with HSA as already described. Untreated BL cells showed similarly low levels of T-cell stimulation, whereas cells treated with bryostatin-1 at 20-40 nM restored Ag presentation and Tcell stimulation (Figure 5(a)). Ramos.DR4 cells were treated with bryostatin-1 overnight, and peptide binding to HLA class II was measured as already described. Ramos.DR4 treated with $40 \mathrm{nM}$ bryostatin-1 showed significantly higher levels of peptide binding at both $10 \mu \mathrm{M}$ and $40 \mu \mathrm{M}$ b-HSA (Figure 5(b)).

\subsection{Bryostatin Treatment Upregulates Expression of an} Immunostimulatory $17 \mathrm{kDa}$ Protein in BL. To determine the nature of the class II presentation restoration in BL following bryostatin-1 treatment, protein expression patterns in CPB eluates from Nalm-6.DR4 and 6.16.DR4.DM were analyzed by gel electrophoresis (non-reducing gel) and coomassie blue staining. This study showed that a $17 \mathrm{kDa}$ protein was consistently expressed at low levels in BL cells (Nalm-6.DR4) but high levels in B-LCL (6.16.DR4.DM) cells (Figure 6(a)). Following overnight treatment of BL cells with bryostatin1 , expression of this $17 \mathrm{kDa}$ protein was restored to levels comparable to 6.16.DR4.DM cells (Figure 6(a)). This protein

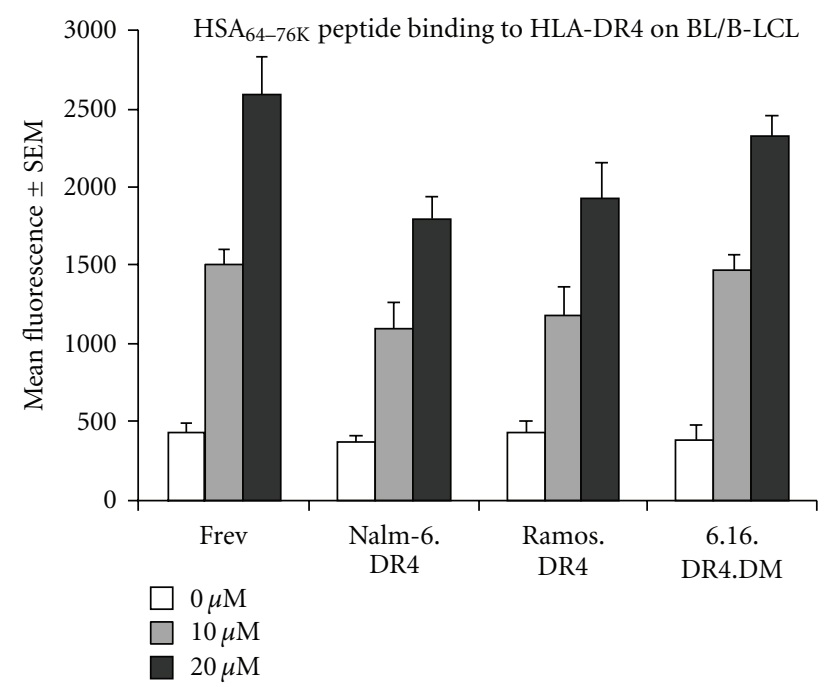

FIGURE 4: BL and B-LCL bind $\mathrm{HSA}_{64-76 \mathrm{~K}}$ synthetic peptide with similar affinity. Ag presentation depends on efficient binding of Ag to HLA class II proteins. BL cell lines Nalm-6.DR4 and Ramos.DR4, and the B-LCL lines 6.16.DR4.DM and Frev were fixed and incubated with biotin-labeled $\mathrm{HSA}_{64-76 \mathrm{~K}}$ at pH 7.4. Cells were lysed and class II peptide complexes were detected in ELISA format with europium-labeled streptavidin with mean fluorescence used as a measure of peptide binding. Each cell line bound similar levels of peptide.

band was then cut from the gel and analyzed by MALDI TOF/TOF mass spectrometry, revealing a peptidylprolyl-like protein (accession number: 89058151). To further analyze the function of this $17 \mathrm{kDa}$ protein, CPB eluates from 6.16.DR4.DM cells or bryostatin-1-treated BL cells were separated on a large non-reducing gel, the band corresponding to $17 \mathrm{kDa}$ protein was excised, and the protein was extracted by sonication in PBS on ice. Ramos.DR4 cells were then incubated with HSA peptide $(10 \mu \mathrm{M})$ in the presence of this extract, followed by washing and co-culture with $17.9 \mathrm{~T}$ cells. ELISA IL-2 quantitation of the assay supernatant showed a significant increase in the stimulation of IL-2 production by Ramos.DR4 cells incubated with HSA in the presence of the $17 \mathrm{kDa}$ extract (Figure 6(b)). These results suggest that bryostatin-1 treatment upregulates expression of a $17 \mathrm{kDa}$ protein in $\mathrm{BL}$, and this protein has an immunostimulatory function.

\section{Discussion}

BL possesses a well-known defect in HLA class I-mediated Ag presentation, resulting from the poor immunogenicity of the EBNA1 protein. EBNA1 possesses an internal Gly-Ala repeat that impairs its proteasomal processing, leading to weak stimulation of CD8+ T cells [35]. This defect, although well studied, addresses only one aspect of the immune response to BL. Less is known about the role of HLA class II-mediated immune responses to this malignancy. Studies have generally focused on CD8+ T-cell responses due to their ability to 


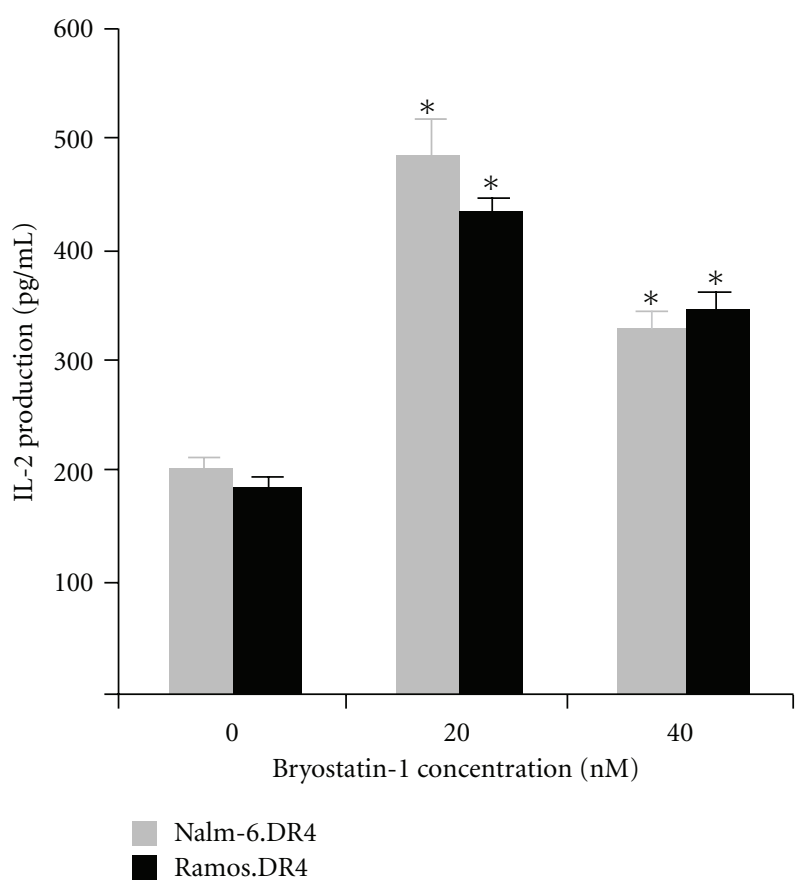

(a) $\mathrm{HSA}_{64-76 \mathrm{k}}$ peptide presentation

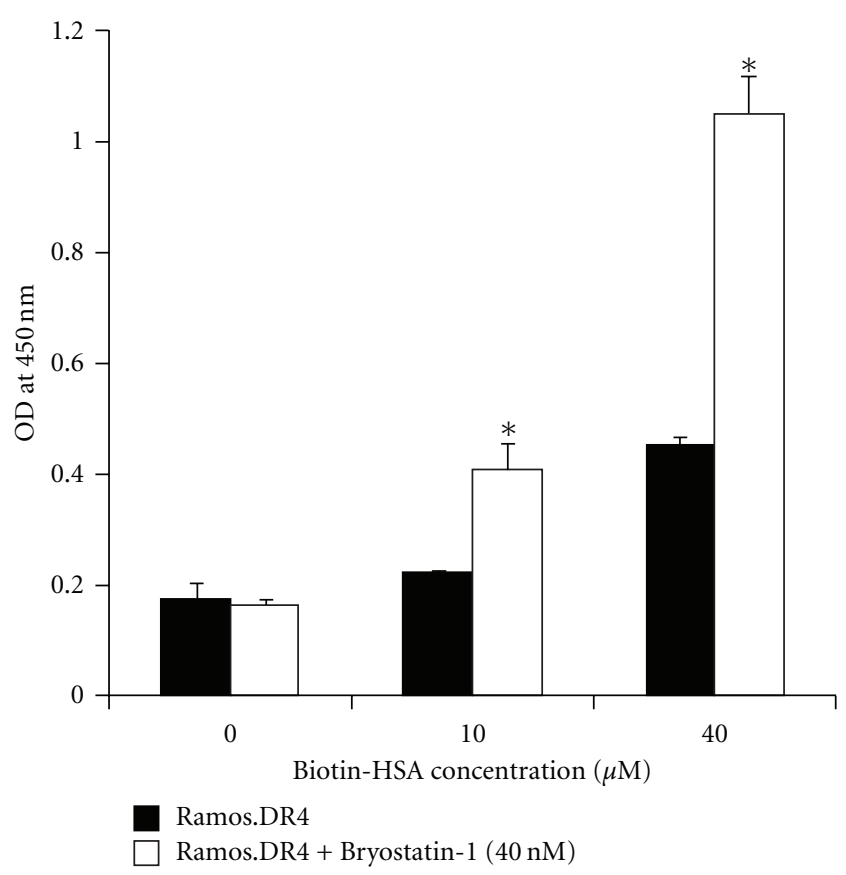

(b) HLA-DR4-HSA $64-76 \mathrm{~K}$ peptide binding

FIGURE 5: Bryostatin treatment increased class II peptide binding and restored class II Ag presentation in BL cell lines. (a) The BL cell lines Nalm-6.DR4 and Ramos.DR4 were treated with 0, 20, or $40 \mathrm{nM}$ bryostatin-1 for $24 \mathrm{~h}$. Following treatment, cells were collected, washed, and incubated with $\mathrm{HSA}_{64-76 \mathrm{~K}}$ synthetic peptide for $24 \mathrm{~h}$. Cells were then washed and co-cultured with the T-cell hybridoma 17.9. Supernatant from the co-culture was assayed by ELISA to determine IL-2 levels as a measure of T-cell stimulation. Results from these assays show that bryostatin-1 treatment significantly restores Ag presentation in both Nalm-6.DR4 and Ramos.DR4 to levels comparable to B-LCL. (b) Ramos.DR4 cells were treated with $40 \mathrm{nM}$ bryostatin overnight and then washed, fixed, and incubated with $0 \mu \mathrm{M}$, $10 \mu \mathrm{M}$, or $40 \mu \mathrm{M}$ of b-HSA for $3 \mathrm{~h}$ at $37^{\circ} \mathrm{C}$ with shaking. The cells were then collected and lysed, and class II/peptide complexes were detected by ELISA. ${ }^{*} P<0.001$.

directly kill target cells, but CD4+ T-cell responses mediated by class II are needed for lasting immune responses and memory $[36,37]$.

In this study, we have shown that although BLs express measurable class II proteins on their cell surface, they were unable to stimulate CD4+ T cells through presentation of HSA peptide or epitope. We demonstrate further that when incubated in buffer at $\mathrm{pH} 5.5, \mathrm{BL}$ cells regain class IImediated Ag presentation capacity. Treatment of BL with bryostatin-1 led to restoration of class II presentation and CD4+ T-cell stimulation. This restoration was due, in part, to the upregulation of a $17 \mathrm{kDa}$, immunostimulatory, peptidylprolyl-like protein which is normally expressed at very low levels in BL, but highly expressed in B-LCL.

The efficiency of class II-mediated Ag presentation to CD4+ $\mathrm{T}$ cells may be partially affected by the expression levels of components in the class II pathway: Ii (invariant chain), HLA-DM and HLA-DO $[26,33,38]$. However, we did not observe any significant differences in the expression levels of these pathway components between two BL and two BLCL cell lines, ruling this out as contributing to the observed defect in BL. CD4+ T cell activation is also dependent on signals delivered by the co-stimulatory molecules, CD80/86, expressed by B cells, yet BLs are known to express lower levels of these molecules [39]. It is plausible that the BLassociated class II defect was a result of insufficient co- stimulation. External co-stimulation may be provided to $\mathrm{T}$ cells in the form of anti-CD28, which serves as a surrogate for $\mathrm{CD} 80 / 86$. While our T-cell hybridomas do not require co-stimulation, we still evaluated whether the decreased expression of co-stimulatory molecules contributed to the BL defect. However, even under these conditions, BL cells were unable to stimulate activation of CD4+ T cells. We gleaned further evidence that co-stimulation is not the cause the BL-associated class II defect from assays demonstrating that cross-linking IgM on BL cells failed to result in CD4+ T-cell stimulation (data not shown).

The presentation of Ag via HLA is central to the immune system's ability to detect pathogens and transformed cells and mount immune responses to these cells. Efficient Ag presentation is dependent on efficient binding of peptides to HLA. While co-stimulation was not the cause of BL's inability to present Ag through class II, the possibility existed that BL-expressed class II was not able to bind Ag efficiently, thus preventing T-cell stimulation. Binding assays, however, demonstrated that BL and B-LCL both bound peptide with a similar, measurable affinity.

Bryostatin-1, a potent modulator of protein kinase C, has previously been shown to stimulate upregulation of HLA class II in colorectal cell lines and dendritic cells and to enhance Ag presentation in dendritic cells [23, 24]. To date, however, its effect on HLA class II expression 


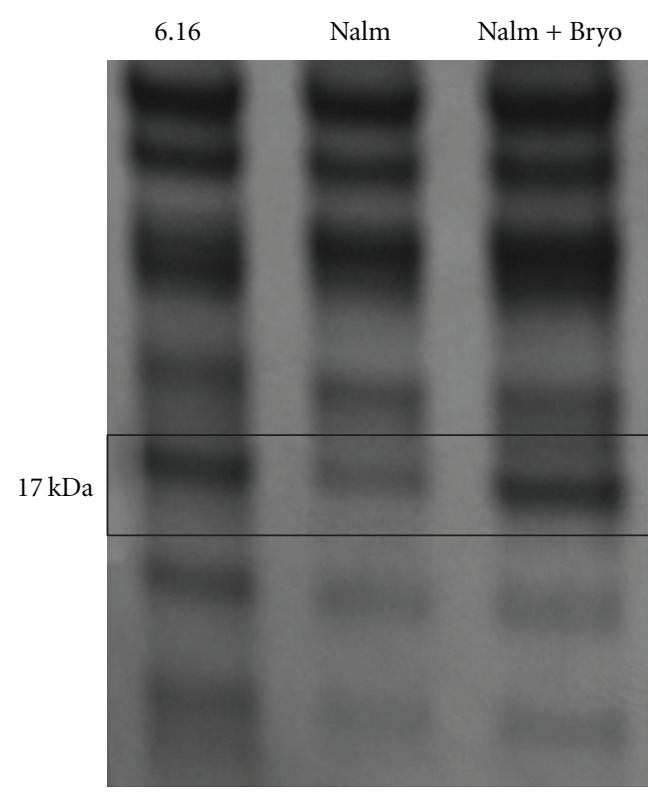

(a)

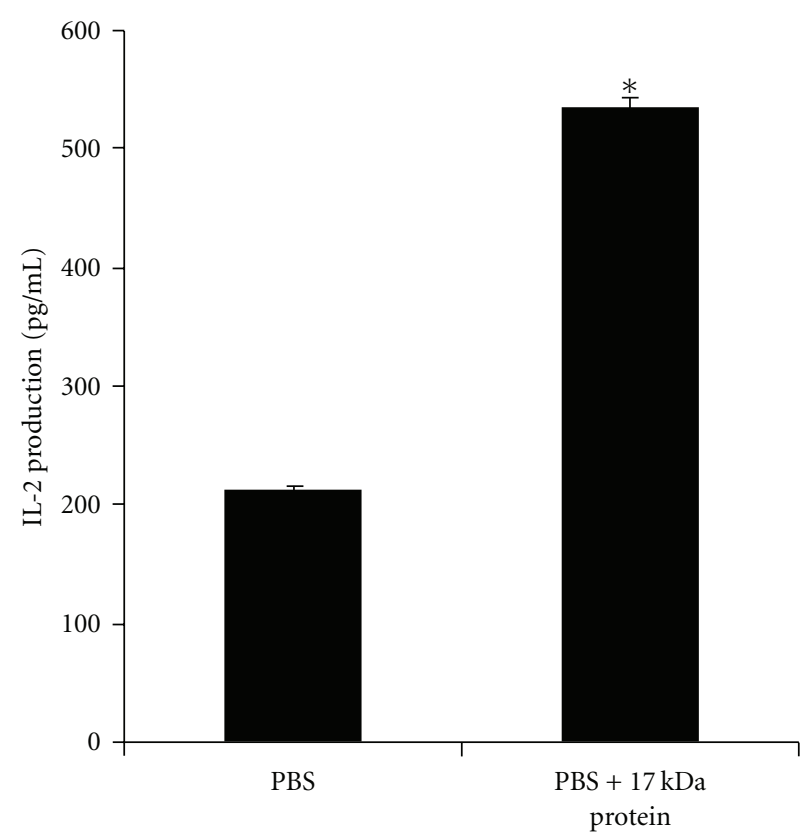

(b)

FIgURE 6: Treatment of BL with bryostatin-1 causes upregulation of a $17 \mathrm{kDa}$ immunostimulatory protein. (a) Acid eluate from Nalm-6.DR4, Nalm-6.DR4 treated for $24 \mathrm{~h}$ with $40 \mathrm{nM}$ bryostatin-1 and 6.16.DR4.DM were collected, and subjected to SDS-PAGE, followed by coomassie blue staining. Gel banding patterns revealed upregulation of a $17 \mathrm{kDa}$ protein in bryostatin-treated Nalm-6.DR4 that is expressed at low levels in untreated Nalm-6.DR4 but highly expressed in 6.16.DR4.DM. (b) Acid eluate from 6.16.DR4.DM was separated on a large, nonreducing gel, the band corresponding to $17 \mathrm{kDa}$ was excised, and the protein was extracted by sonication in PBS on ice. Ramos.DR4 cells were then incubated in PBS or $17 \mathrm{kDa}$ gel extract with $\mathrm{HSA}_{64-76 \mathrm{~K}}$ synthetic peptide. Cells were then washed and co-cultured with the T-cell hybridoma line 17.9. Supernatant from the co-culture was assayed by ELISA to determine IL-2 levels as a measure of T-cell stimulation. Results show that IL-2 stimulation is significantly increased in Ramos.DR4 cells incubated with peptide in the presence of the $17 \mathrm{kDa}$ gel extract. *indicates $P<0.05$.

and $\mathrm{Ag}$ presentation in lymphoid malignancies has not been evaluated. Based on this information, we sought to determine if treatment with bryostatin-1 was sufficient to enable restoration of class II-mediated Ag presentation to BL. We found that the BL cell lines Nalm-6.DR4 and Ramos.DR4 did indeed regain HLA class II Ag presentation capacity following treatment with bryostatin-1. Our assays with Ramos.DR4 cells demonstrated that restoration of HLA class II Ag presentation could partially be due to increased peptide binding by HLA class II following treatment with bryostatin-1. Additionally, protein expression analysis following bryostatin-1 treatment showed a marked increase in a $17 \mathrm{kDa}$ peptidylprolyl-like protein in Nalm-6.DR4, which was expressed at very low levels in untreated Nalm6.DR4 and expressed at high levels in 6.16.DR4.DM. This protein, when extracted and used in Ag presentation assays, enhanced class II-mediated Ag presentation in 6.16.DR4.DM cells. Thus, bryostatin-induced restoration of class II Ag presentation in BL cells was mediated by an increased expression of a peptidylprolyl-like protein.

$\mathrm{BL}$ is a rapidly growing malignancy and thus requires aggressive chemotherapy to control its spread. Currently used chemotherapy regimens have achieved high cure rates in both adults and children, but treatment-associated toxicities are problematic. This issue is of particular concern for elderly and HIV-infected patients who show inferior responses and reduced tolerance of treatment-associated toxicities [40]. Treatment success has improved with the use of anti-CD20 monoclonal antibody, rituximab [41]. However, toxicities remain problematic, and the use of an immunosuppressive in HIV-infected patients is a subject of ongoing debate [42, 43]. While current treatments for BL have shown overall success, there is obvious room for improvement in the treatment of elderly and HIV-infected patients. Our future studies will continue to evaluate the role of bryostatin- 1 in restoring class II-mediated Ag presentation in $\mathrm{BL}$ and determine the immunostimulatory role of the peptidylprolyl-like protein. A better understanding of these factors may lead to development of novel immunotherapies which could augment, lessen, or eliminate the need for toxic chemotherapies.

\section{Authors' Contribution}

Azim Hossain and Jason M. God contributed equally to this paper.

\section{Acknowledment}

We thank Dr. Janice Blum (Indiana University School of Medicine) for providing cell lines and reagents, and Dr. 
Daniel Knapp (Department of Pharmacology) for mass spectrometry facility and technical assistance. This work was supported by grants from the National Institutes of Health (5R01CA129560 and CA129560-S1) to A. Haque. The research presented in this article was also supported in part by the Tissue Biorepository and Flow Cytometry Shared Resource as part of the Hollings Cancer Center at the Medical University of South Carolina which is funded by a Cancer Center Support Grant P30 CA138313.

\section{References}

[1] G. Brady, G. J. MacArthur, and P. J. Farrell, "Epstein-Barr virus and Burkitt lymphoma," Postgraduate Medical Journal, vol. 84, no. 993, pp. 372-377, 2008.

[2] A. S. Perkins and J. W. Friedberg, "Burkitt lymphoma in adults," Hematology, pp. 341-348, 2008.

[3] D. M. Biko, S. A. Anupindi, A. Hernandez, L. Kersun, and R. Bellah, "Childhood Burkitt lymphoma: abdominal and pelvic imaging findings," American Journal of Roentgenology, vol. 192, no. 5, pp. 1304-1315, 2009.

[4] J. T. Yustein and C. V. Dang, "Biology and treatment of Burkitt's lymphoma," Current Opinion in Hematology, vol. 14, no. 4, pp. 375-381, 2007.

[5] K. Kawa, "Diagnosis and treatment of Epstein-Barr virusassociated natural killer cell lymphoproliferative disease," International Journal of Hematology, vol. 78, no. 1, pp. 24-31, 2003.

[6] A. L. Snow and O. M. Martinez, "Epstein-Barr virus: evasive maneuvers in the development of PTLD," American Journal of Transplantation, vol. 7, no. 2, pp. 271-277, 2007.

[7] R. F. Ambinder, "Epstein-barr virus and hodgkin lymphoma," Hematology, pp. 204-209, 2007.

[8] H. Ohtsubo, N. Arima, and C. Tei, "Epstein-Barr virus involvement in T-cell malignancy: significance in adult T-cell leukemia," Leukemia and Lymphoma, vol. 33, no. 5-6, pp. 451458, 1999.

[9] C. V. Dang, K. A. O’Donnell, K. I. Zeller, T. Nguyen, R. C. Osthus, and F. Li, "The c-Myc target gene network," Seminars in Cancer Biology, vol. 16, no. 4, pp. 253-264, 2006.

[10] C. Bellan, S. Lazzi, M. Hummel et al., "Immunoglobulin gene analysis reveals 2 distinct cells of origin for EBV-positive and EBV-negative Burkitt lymphomas," Blood, vol. 106, no. 3, pp. 1031-1036, 2005.

[11] S. S. Dave, K. Fu, G. W. Wright et al., "Molecular diagnosis of Burkitt's lymphoma," New England Journal of Medicine, vol. 354, no. 23, pp. 2431-2442, 2006.

[12] A. Gerbitz, J. Mautner, C. Geltinger et al., "Deregulation of the proto-oncogene $\mathrm{c}$-myc through $\mathrm{t}(8 ; 22)$ translocation in Burkitt's lymphoma," Oncogene, vol. 18, no. 9, pp. 1745-1753, 1999.

[13] T. Frisan, V. Levitsky, A. Polack, and M. G. Masucci, "Phenotype-dependent differences in proteasome subunit composition and cleavage specificity in B cell lines," Journal of Immunology, vol. 160, no. 7, pp. 3281-3289, 1998.

[14] A. Sharipo, M. Imreh, A. Leonchiks, S. Imreh, and M. G. Masucci, "A minimal glycine-alanine repeat prevents the interaction of ubiquitinated $\mathrm{I} \kappa \mathrm{B} \alpha$ with the proteasome: a new mechanism for selective inhibition of proteolysis," Nature Medicine, vol. 4, no. 8, pp. 939-944, 1998.

[15] Y. Yin, B. Manoury, and R. Fåhraeus, "Self-inhibition of synthesis and antigen presentation by Epstein-Barr virus- encoded EBNA1," Science, vol. 301, no. 5638, pp. 1371-1374, 2003.

[16] M. G. Masucci, S. Torsteinsdottir, J. Colombani, C. Brautbar, E. Klein, and G. Klein, "Down-regulation of class I HLA antigens and of the Epstein-Barr virus-encoded latent membrane protein in Burkitt lymphoma lines," Proceedings of the National Academy of Sciences of the United States of America, vol. 84, no. 13, pp. 4567-4571, 1987.

[17] R. Gavioli, P. O. De Campos-Lima, M. G. Kurilla, E. Kieff, G. Klein, and M. G. Masucci, "Recognition of the EpsteinBarr virus-encoded nuclear antigens EBNA-4 and EBNA-6 by HLA-A11-restricted cytotoxic T lymphocytes: implications for down- regulation of HLA-A11 in Burkitt lymphoma," Proceedings of the National Academy of Sciences of the United States of America, vol. 89, no. 13, pp. 5862-5866, 1992.

[18] W. Jilg, R. Voltz, C. Markert-Hahn, H. Mairhofer, I. Munz, and H. Wolf, "Expression of class I major histocompatibility complex antigens in Epstein-Barr virus-carrying lymphoblastoid cell lines and Burkitt lymphoma cells," Cancer Research, vol. 51, no. 1, pp. 27-32, 1991.

[19] M. E. Ressing, D. van Leeuwen, F. A. Verreck et al., "Interference with T cell receptor-HLA-DR interactions by EpsteinBarr virus gp42 results in reduced T helper cell recognition," Proceedings of the National Academy of Sciences of the United States of America, vol. 100, no. 20, pp. 11583-11588, 2003.

[20] M. E. Ressing, D. van Leeuwen, F. A. Verreck et al., "EpsteinBarr virus gp42 is posttranslationally modified to produce soluble gp42 that mediates HLA class II immune evasion," Journal of Virology, vol. 79, no. 2, pp. 841-852, 2005.

[21] F. G. Gao, V. Khammanivong, W. J. Liu, G. R. Leggatt, I. H. Frazer, and G. J. P. Fernando, "Antigen-specific CD4 ${ }^{+}$T-cell help is required to activate a memory $\mathrm{CD}^{+} \mathrm{T}$ cell to a fully functional tumor killer cell," Cancer Research, vol. 62, no. 22, pp. 6438-6441, 2002.

[22] S. Amria, C. Cameron, R. Stuart, and A. Haque, "Defects in HLA class II antigen presentation in B-cell lymphomas," Leukemia and Lymphoma, vol. 49, no. 2, pp. 353-355, 2008.

[23] Y. Do, V. L. Hegde, P. S. Nagarkatti, and M. Nagarkatti, "Bryostatin-1 enhances the maturation and antigenpresenting ability of murine and human dendritic cells," Cancer Research, vol. 64, no. 18, pp. 6756-6765, 2004.

[24] Y. Kudinov, C. L. Wiseman, and A. I. Kharazi, "Phorbol myristate acetate and bryostatin 1 rescue IFN-gamma inducibility of MHC class II molecules in LS1034 colorectal carcinoma cell line," Cancer Cell International, vol. 3, article 4, 2003.

[25] M. A. Haque, J. W. Hawes, and J. S. Blum, "Cysteinylation of MHC class II ligands: peptide endocytosis and reduction within APC influences T cell recognition," Journal of Immunology, vol. 166, no. 7, pp. 4543-4551, 2001.

[26] A. Haque, L. M. Hajiaghamohseni, P. Li, K. Toomy, and J. S. Blum, "Invariant chain modulates HLA class II protein recycling and peptide presentation in nonprofessional antigen presenting cells," Cellular Immunology, vol. 249, no. 1, pp. 2029, 2007.

[27] A. Hiraiwa, K. Yamanaka, W. W. Kwok et al., "Structural requirements for recognition of the HLA-Dw14 class II epitope: a key HLA determinant associated with rheumatoid arthritis," Proceedings of the National Academy of Sciences of the United States of America, vol. 87, no. 20, pp. 8051-8055, 1990.

[28] C. Ma, P. E. Whiteley, P. M. Cameron et al., "Role of APC in the selection of immunodominant T cell epitopes," Journal of Immunology, vol. 163, no. 12, pp. 6413-6423, 1999. 
[29] S. S. Pathak and J. S. Blum, "Endocytic recycling is required for the presentation of an exogenous peptide via MHC class II molecules," Traffic, vol. 1, no. 7, pp. 561-569, 2000.

[30] M. A. Haque, P. Li, S. K. Jackson et al., "Absence of $\gamma$ interferon-inducible lysosomal thiol reductase in melanomas disrupts $\mathrm{T}$ cell recognition of select immunodominant epitopes," Journal of Experimental Medicine, vol. 195, no. 10, pp. 1267-1277, 2002

[31] A. R. Younger, S. Amria, W. A. Jeffrey et al., "HLA class II antigen presentation by prostate cancer cells," Prostate Cancer and Prostatic Diseases, vol. 11, no. 4, pp. 334-341, 2008.

[32] O. G. Goldstein, L. M. Hajiaghamohseni, S. Amria, K. Sundaram, S. V. Reddy, and A. Haque, "Gamma-IFN-induciblelysosomal thiol reductase modulates acidic proteases and HLA class II antigen processing in melanoma," Cancer Immunology, Immunotherapy, vol. 57, no. 10, pp. 1461-1470, 2008.

[33] S. Amria, L. M. Hajiaghamohseni, C. Harbeson et al., "HLA-DM negatively regulates HLA-DR4-restricted collagen pathogenic peptide presentation and T cell recognition," European Journal of Immunology, vol. 38, no. 7, pp. 1961-1970, 2008.

[34] C. M. Hill, A. Liu, K. W. Marshall et al., "Exploration of requirements for peptide binding to HLA DRB1*0101 and DRB1*0401," Journal of Immunology, vol. 152, no. 6, pp. 2890 2898, 1994.

[35] R. Khanna, S. R. Burrows, S. A. Thomson et al., "Class I processing-defective burkitt's lymphoma cells are recognized efficiently by CD4 ${ }^{+}$EBV-specific CTLs," Journal of Immunology, vol. 158, no. 8, pp. 3619-3625, 1997.

[36] M. Matloubian, R. J. Concepcion, and R. Ahmed, "CD4 ${ }^{+} \mathrm{T}$ cells are required to sustain $\mathrm{CD}^{+}$cytotoxic T-cell responses during chronic viral infection," Journal of Virology, vol. 68, no. 12, pp. 8056-8063, 1994.

[37] J. Q. Mi, O. Manches, J. Wang et al., "Development of autologous cytotoxic $\mathrm{CD} 4^{+} \mathrm{T}$ clones in a human model of B-cell non-Hodgkin follicular lymphoma," British Journal of Haematology, vol. 135, no. 3, pp. 324-335, 2006.

[38] H. Khalil, F. Deshaies, A. Bellemare-Pelletier et al., "Class II transactivator-induced expression of HLA-DO $\beta$ in Hela cells," Tissue Antigens, vol. 60, no. 5, pp. 372-382, 2002.

[39] M. S. Staege, S. P. Lee, T. Frisan et al., "MYC overexpression imposes a nonimmunogenic phenotype on Epstein-Barr virus-infected B cells," Proceedings of the National Academy of Sciences of the United States of America, vol. 99, no. 7, pp. 45504555, 2002.

[40] I. T. Aldoss, D. D. Weisenburger, K. Fu et al., "Adult Burkitt lymphoma: advances in diagnosis and treatment," Oncology, vol. 22, no. 13, pp. 1508-1517, 2008.

[41] D. A. Thomas, S. Faderl, S. O’Brien et al., "Chemoimmunotherapy with hyper-CVAD plus rituximab for the treatment of adult Burkitt and Burkitt-type lymphoma or acute lymphoblastic leukemia," Cancer, vol. 106, no. 7, pp. 15691580, 2006.

[42] A. Oriol, J. M. Ribera, J. Bergua et al., "High-dose chemotherapy and immunotherapy in adult Burkitt lymphoma: comparison of results in human immunodeficiency virus-infected and noninfected patients," Cancer, vol. 113, no. 1, pp. 117-125, 2008.

[43] J. C. Gea-Banacloche, "Rituximab-associated infections," Seminars in Hematology, vol. 47, no. 2, pp. 187-198, 2010. 


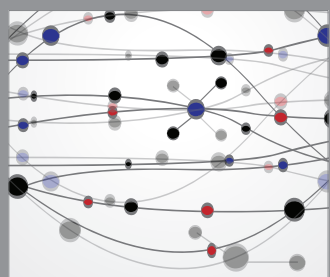

The Scientific World Journal
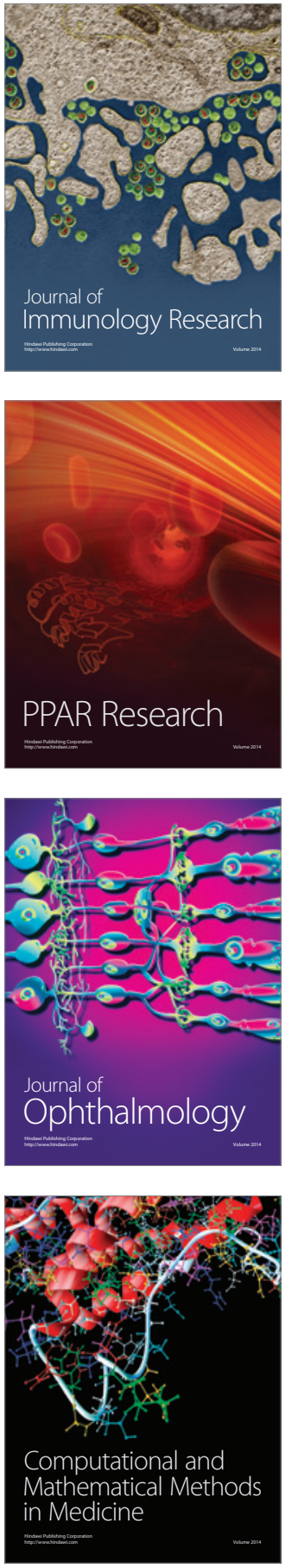

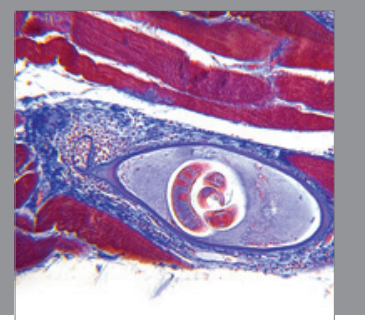

Gastroenterology

Research and Practice
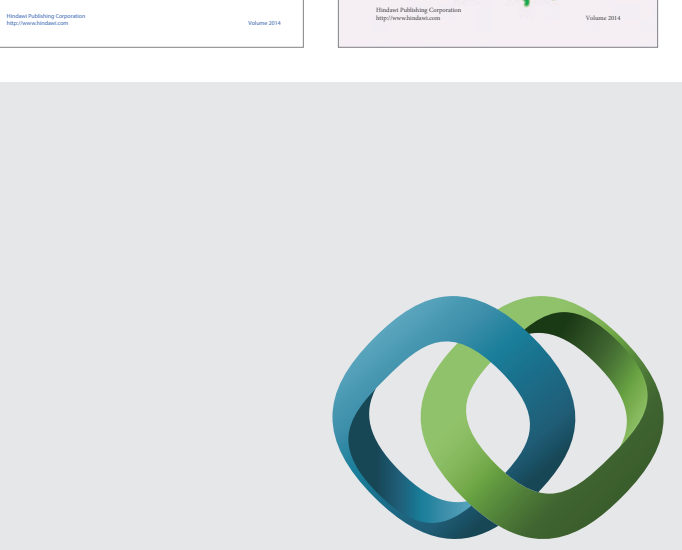

\section{Hindawi}

Submit your manuscripts at

http://www.hindawi.com
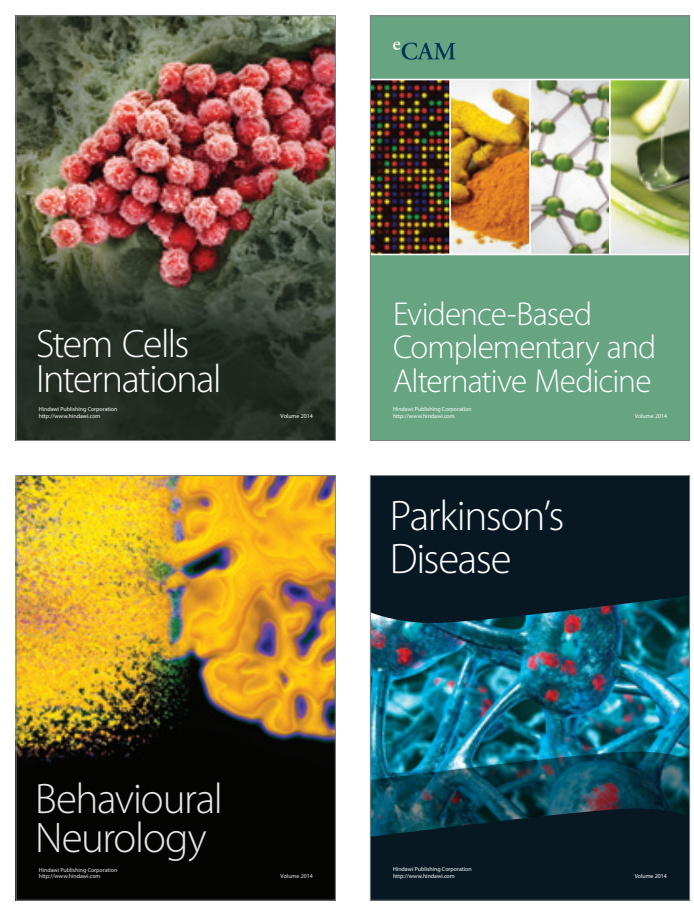

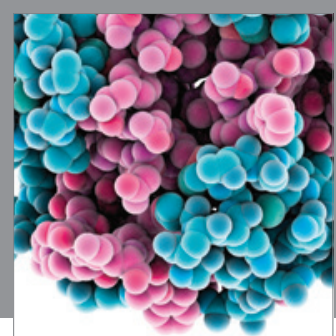

Journal of
Diabetes Research

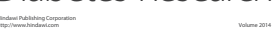

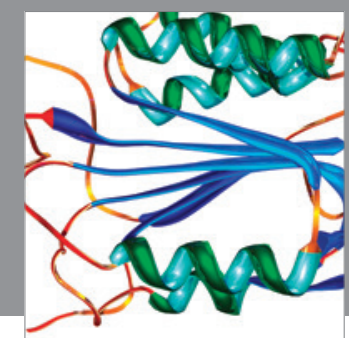

Disease Markers
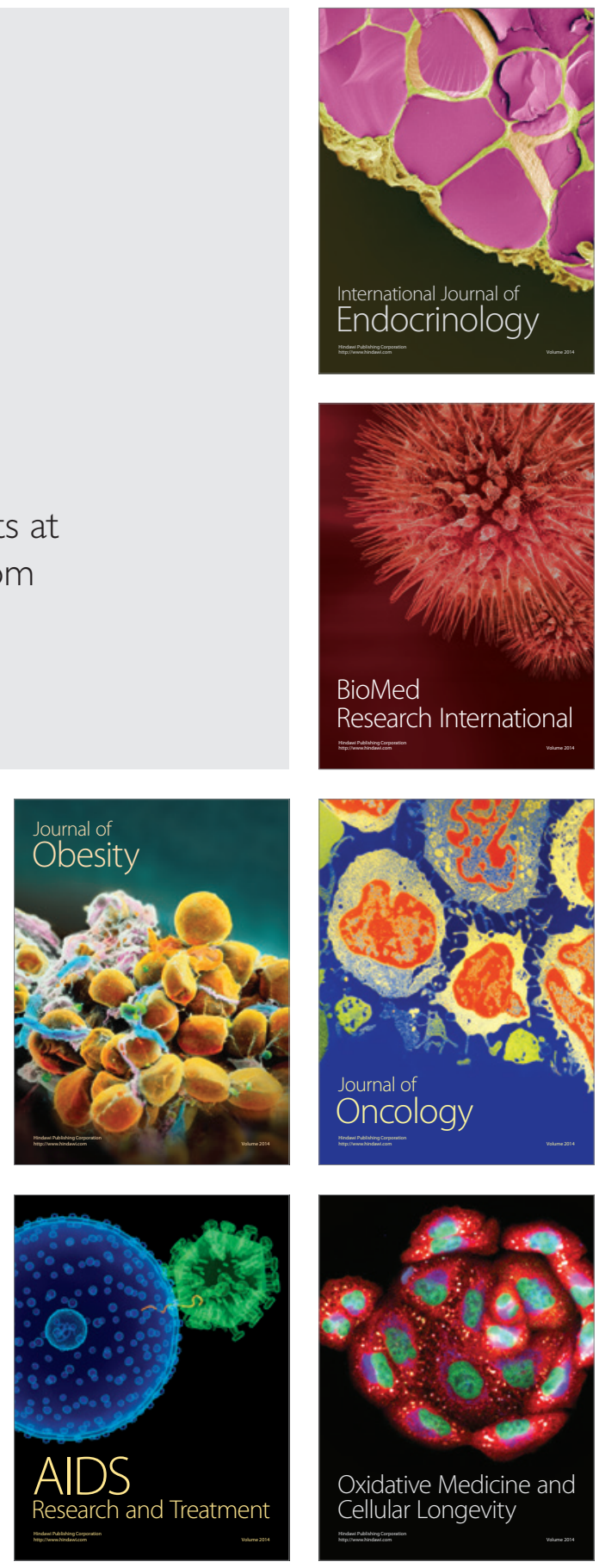